\title{
Effects of risk factor numbers on the development of the metabolic syndrome
}

\author{
Jangwon Lee ${ }^{1, *}$, Hyunju Lee ${ }^{2}$ \\ 'Department of Sports Industry, College of Sports, Jungwon University, Goesan, Korea \\ ${ }^{2}$ Department of Health Administration, College of Medical Health, Jungwon University, Goesan, Korea
}

This study was performed to identify the factors affecting the development of metabolic syndrome by comparing the numbers of risk factors of the syndrome and by identifying the factors influencing the development of metabolic syndrome. Two hundred forty-eight health screening of examinee were used for the study (101 males, 147 females). Diagnostic basis ratio of metabolic syndrome risk factors showed that $35.1 \%$ of the subjects had abdominal obesity, $32.7 \%$ for high blood pressure, $66.1 \%$ for high insulin blood sugar, $43.1 \%$ for high triglyceride lipidemia, and $7.3 \%$ for low high-density lipoprotein lipidemia. No significant difference of the incidence of metabolic syndrome was found between gender. The diagnostic number for male was the highest with 1 risk factor
$(31.7 \%)$ while the highest with 2 factors $(30.6 \%)$ in female. Significant differences were found in age and body mass index (BMI) between normal group with no risk factor and metabolic syndrome group. There was significant difference in BMI between the syndrome group with 1 risk factor and 3 risk factors. BMI was significantly higher (5.282 times) compared to their counterpart $(P<0.001)$. Significant difference was found in BMI between 2 risk factors and the syndrome group with more than 3 risk factors and the incidence was higher (4.094 times) in the overweight group than their counterpart $(P<0.001)$.

Keywords: Metabolic syndrome, Risk factor

\section{INTRODUCTION}

Metabolic syndrome is used since Reaven proposed the term which is called 'x syndrome' in 1988. Five risk factors for diagnosing metabolic syndrome include conditions of increased fat around waist, high insulin blood sugar, increased blood pressure, and abnormal cholesterol or triglyceride levels (Reaven, 1988). More than 3 risk factors are considered as metabolic syndrome while 1 or 2 factors are considered as metabolic risk group (Kim et al., 2012; National Health Insurance Service, 2016).

According to the National Health Screening Statistical Yearbook published by National Health Insurance Service (2018), 26\% of health examinee were found to be metabolic syndrome patients. The population of the patient is increasing every year (Moore et al, 2017; National Health Insurance Service, 2016): 22.1\% in $2014,24.0 \%$ in $2015,25.0 \%$ in 2016 (National Health Insur- ance Service, 2016, 2017). On the contrary, the population of the normal group and metabolic risk group is decreasing every year since 2014. This means that the transition rate from 0 of normal to 2 risk factors of metabolic syndrome is steadily increasing compared to the past (Pickens et al., 2018). From that reason, it is necessary to provide rapid and proper mediation and to identify the related mediation factors.

Generally, metabolic syndrome is closely related with smoking, drinking alcohol, obesity, body mass index (BMI), gender, age, stress, exercise, hypertension, chronic disease, family history, and concerns on health (Fan et al., 2019; Jamee et al., 2019; Li et al., 2016; Mercado et al., 2015; Pérez et al., 2019; Yahia et al., 2017).

Therefore, the purpose of this study was to identify the factors affecting the development of metabolic syndrome by comparing the number of risk factors of the syndrome and by identifying the factors influencing the development of the syndrome.
${ }^{\star}$ Corresponding author: Jangwon Lee (D) https://orcid.org/0000-0002-1086-3323 Department of Sports Industry, College of Sports, Jungwon University,

85 Munmu-ro, Goesan-eup, Goesan 28024, Korea

E-mail: jlee@jwu.ac.kr

Received: February 2, 2020 / Accepted: March 25, 2020
This is an Open Access article distributed under the terms of the Creative Commons Attribution Non-Commercial License (https://creativecommons.org/licenses/by-nc/4.0/) which permits unrestricted non-commercial use, distribution, and reproduction in any medium, provided the original work is properly cited. 
Table 1. Diagnostic criteria for risk factors of metabolic syndrome

\begin{tabular}{|c|c|c|}
\hline Risk factors & Diagnostic criteria & No. of risk factors \\
\hline Abdominal obesity & M: above $90 \mathrm{~cm}$, F: above $85 \mathrm{~cm}$ & \multirow{5}{*}{$\begin{array}{l}\text { 0: normal } \\
\text { 1-2: risk group } \\
\text { Above } 3 \text { : } \\
\text { metabolic } \\
\text { syndrome }\end{array}$} \\
\hline High blood pressure & Above $130 / 85 \mathrm{mmHg}$ & \\
\hline High insulin blood sugar & $\begin{array}{l}\text { Above } 100 \mathrm{mg} / \mathrm{dL} \text { during empty } \\
\text { stomach }\end{array}$ & \\
\hline High triglyceride lipidemia & Above $50 \mathrm{mg} / \mathrm{dL}$ & \\
\hline Low density lipidemia & $\begin{array}{l}\text { M: below } 40 \mathrm{mg} / \mathrm{dL}, \\
\text { F: below } 50 \mathrm{mg} / \mathrm{dL}\end{array}$ & \\
\hline
\end{tabular}

M, male; F, female.

\section{MATERIALS AND METHODS}

\section{Participants}

Two hundred forty-eight health screening examinee participated for the study (101 males, 147 females). They were screened between January to May in 2019 in Chungbuk providence. All subjects were screened and individuals were removed from the test if they had no cholesterol values.

\section{Experimental design}

\section{Diagnostic criteria for risk factors of metabolic syndrome}

Diagnostic criteria for risk factors of metabolic syndrome are listed in Table 1 . The results of the risk factors were got by utilizing the results of health screening (Kim et al., 2012; National Health Insurance Service, 2016).

\section{Data collecting}

In order to identify the differences among the other groups of metabolic syndrome, general characteristics include variances as follows: residential district, gender, age, current and past smoking history, number of days of weekly drinking alcohol, number of days of weekly intensive exercise, and chronic disease of family members. Total cholesterol and BMI were chosen as clinical characteristics because of their identification thru health screening questionnaire. The summary of general characteristics of variances is shown in Table 2.

\section{Statistical analysis}

Data were analyzed with PASW Statistics ver. 18.0 (SPSS Inc., Chicago, IL, USA) and statistical significance was set at $P<0.05$. The frequency analysis was used to identify the ratio of diagnostic numbers of metabolic syndrome risk factors, and chi-square test and one-way analysis of variance were utilized for general and clinical characteristics. Two-way logistic regression was performed to identify the influential factors for the diagnostic numbers of the
Table 2. Summary of general characteristics of variances

\begin{tabular}{l} 
Characteristic \\
Residential district \\
Small \\
Medium \\
Large \\
Gender \\
Male \\
Female \\
Current age \\
Current smoking \\
Nonsmoker \\
Past smoker \\
Current smoker \\
Smoking history \\
Length of smoking (yr) \\
Ouantity of smoking (no. of cigarettes/1 day) \\
Numbers of drinking alcohol (number/1 wk) \\
Numbers of intensive exercise (number/1 wk) \\
Chronic disease of family members \\
No \\
Yes \\
Total cholesterol (mg/dL) \\
Body mass index (kg/m²) \\
Normal (18.5-24.9) \\
Overweight (25.0-29.9) \\
Obesity ( $\geq 30$ ) \\
\hline
\end{tabular}

metabolic syndrome risk factors.

\section{RESULTS}

\section{Diagnostic criteria ratio of risk factors of metabolic syndrome}

According to the results of the ratio of which 5 diagnostic criteria based on the gender, $35.1 \%$ of the subjects had abdominal obesity, $32.7 \%$ for high blood pressure, $66.1 \%$ for high insulin blood sugar, $43.1 \%$ for high triglyceride lipidemia, and $7.3 \%$ for low highdensity lipoprotein (HDL) lipidemia, respectively. There was no significant difference of the incidence of metabolic syndrome between gender, while the incidence of abdominal obesity, high triglyceride lipidemia, and low HDL lipidemia were higher in women compared to their counterpart. The ratio of risk factors for the metabolic syndrome are shown in Table 3.

\section{General and clinical characteristics of diagnostic numbers of metabolic syndrome risk factors}

General and clinical characteristics were identified by separating 
Table 3. Ratios of risk factors for metabolic syndrome (\%)

\begin{tabular}{lcccccc}
\hline Gender & $\begin{array}{c}\text { Abdominal obesity } \\
(\%)\end{array}$ & $\begin{array}{c}\text { High blood pressure } \\
(\mathrm{mmHg})\end{array}$ & $\begin{array}{c}\text { High insulin blood sugar } \\
(\mathrm{mg} / \mathrm{dL})\end{array}$ & $\begin{array}{c}\text { High TG lipidemia } \\
(\mathrm{mg} / \mathrm{dL})\end{array}$ & $\begin{array}{c}\text { Low HDL lipidemia } \\
(\mathrm{mg} / \mathrm{dL})\end{array}$ & $\begin{array}{c}\text { Incidence of the syndrome } \\
(\%)\end{array}$ \\
\hline Male & 28.7 & 37.6 & 67.3 & 41.6 & 5.0 & 28.6 \\
Female & 39.5 & 29.3 & 65.3 & 44.2 & 8.8 & 28.7 \\
Total & 35.1 & 32.7 & 66.1 & 43.1 & 7.3 & 28.6 \\
\hline
\end{tabular}

TG, triglyceride; HDL, high-density lipidemia.

Table 4. General and clinical characteristics of metabolic syndrome according to the diagnostic numbers

\begin{tabular}{|c|c|c|c|c|c|c|}
\hline \multirow{2}{*}{ Variable } & \multicolumn{5}{|c|}{ Diagnostic numbers } & \multirow{2}{*}{$\chi^{2} / f /$ tvalue } \\
\hline & $0(n=31)$ & $1(n=73)$ & $2(n=73)$ & $\geq 3(n=71)$ & Total $(n=248)$ & \\
\hline Residence & Small & Small & Small & Small & Small & \\
\hline \multicolumn{7}{|l|}{ Gender } \\
\hline Male & $12(11.9)$ & 32 (31.7) & $28(27.7)$ & $29(28.7)$ & $101(100)$ & 0.515 \\
\hline Female & $19(12.9)$ & $41(27.9)$ & $45(30.6)$ & $42(28.6)$ & $147(100)$ & \\
\hline Age (yr) & $66.8 \pm 13.94^{\mathrm{a}}$ & $72.6 \pm 12.06^{\mathrm{ab}}$ & $73.3 \pm 10.09^{b}$ & $70.0 \pm 10.59^{\mathrm{ab}}$ & $71.3 \pm 11.50$ & $3.024^{*}$ \\
\hline \multicolumn{7}{|l|}{ Smoking } \\
\hline Non & $27(87.1)$ & 60 (82.2) & $63(86.3)$ & $60(84.5)$ & $210(84.7)$ & 0.637 \\
\hline Past & $4(12.9)$ & $13(17.8)$ & $10(13.7)$ & $11(13.7)$ & $38(15.3)$ & \\
\hline Current & $0(0)$ & $0(0)$ & $0(0)$ & $0(0)$ & $0(0)$ & \\
\hline \multicolumn{7}{|l|}{ Past smoking } \\
\hline Duration (yr) & $30.0 \pm 10.80^{a}$ & $42.3 \pm 11.66^{\mathrm{a}}$ & $22.9 \pm 17.92^{\mathrm{a}}$ & $35.5 \pm 16.95^{a}$ & $33.9 \pm 16.41$ & $3.244^{*}$ \\
\hline Number/day & $10.0 \pm 7.07^{a}$ & $14.6 \pm 6.91^{\mathrm{a}}$ & $24.5 \pm 18.92^{\mathrm{a}}$ & $16.6 \pm 8.44^{a}$ & $17.3 \pm 12.18$ & 2.023 \\
\hline No. of drinking/wk & $0.7 \pm 1.21^{\mathrm{a}}$ & $1.1 \pm 1.92^{\mathrm{a}}$ & $0.8 \pm 1.58^{a}$ & $1.1 \pm 1.92^{\mathrm{a}}$ & $1.0 \pm 1.75$ & 0.708 \\
\hline No. of intensive ex/wk & $1.9 \pm 2.14^{\mathrm{a}}$ & $2.1 \pm 2.59^{a}$ & $2.4 \pm 2.89^{a}$ & $2.6 \pm 2.79^{a}$ & $2.3 \pm 2.68$ & 0.653 \\
\hline Chronic disease, yes & $3(9.7)$ & $12(16.4)$ & $11(15.1)$ & $17(23.9)$ & $43(17.3)$ & 3.734 \\
\hline Family history, no & $28(90.3)$ & $61(83.6)$ & $62(84.9)$ & $54(84.9)$ & $205(76.1)$ & \\
\hline Total cholesterol (mg/dL) & $193.3 \pm 34.07^{\mathrm{a}}$ & $198.5 \pm 37.85^{a}$ & $208.9 \pm 46.06^{a}$ & $201.7 \pm 40.7^{\mathrm{a}}$ & $201.8 \pm 40.9$ & 1.334 \\
\hline \multicolumn{7}{|l|}{ Body mass index (kg/m²) } \\
\hline Mean & $23.1 \pm 2.55^{\mathrm{a}}$ & $23.5 \pm 3.75^{a}$ & $24.0 \pm 3.02^{\mathrm{a}}$ & $26.5 \pm 2.86^{b}$ & $24.4 \pm 3.41$ & $14.301^{* * *}$ \\
\hline Normal & $24(77.4)$ & $50(68.4)$ & $48(65.7)$ & $23(32.4)$ & $145(58.4)$ & $33.507^{* * *}$ \\
\hline$\geq$ Overweight & $7(22.6)$ & $23(31.5)$ & $25(34.3)$ & $48(67.6)$ & $103(41.5)$ & \\
\hline Total & $31(100)$ & $73(29.4)$ & $73(29.4)$ & $71(28.6)$ & $248(100)$ & \\
\hline
\end{tabular}

Values are presented as number (\%) or mean \pm standard deviation.

${ }^{*} P<0.05$. ${ }^{* *} P<0.001$. a $<$ b (Scheffe).

the numbers of the risk factors into $0,1,2$, and above 3 according to the results of the health screening. Table 4 shows the results.

In gender, the diagnostic numbers and ratios of risk factor for male are as follows: highest with 1 (31.7\%), above 3 (28.7\%), $2(27.7 \%)$, and $0(11.9 \%)$, respectively. On the contrary, female showed different order: highest with 2 (30.6\%), above $3(28.6 \%)$, 1 (27.9), and $0(12.9 \%)$, respectively.

The average age was 71.3 years and the highest ( 73.3 years) was the group with 2 diagnostic numbers, and the lowest (66.8 years) with diagnostic number with 0 . There were significant average age differences among groups $(P<0.05)$. the ratio of past smoking was the lowest (12.9\%) in the group with the diagnostic number with 0 . The average number of days of drinking alcohol weekly was 1.0 and number of days of weekly intensive exercise was 2.3. No significant difference was found among groups. For the family history of chronic disease, it was found that average was $17.3 \%$ and the average was the lowest $(9.7 \%)$ in the group of diagnostic number with 0 . The average total cholesterol was $201.8 \mathrm{mg} / \mathrm{dL}$ and the lowest $(193.3 \mathrm{mg} / \mathrm{dL})$ in the group of diagnostic number with 0 . The average BMI was $24.4 \mathrm{~kg} / \mathrm{m}^{2}$ and the average increased proportionally as the diagnostic numbers increase showing significant differences among groups $(P<0.001)$. Also, the group with the highest ratio $(77.4 \%)$ of normal BMI $(18.5 \%-24.9 \%)$ was the group with diagnostic number of 0 . On the contrary, the group 
with the diagnostic numbers of above 3 was the lowest (32.4\%) $(P<0.001)$.

\section{Comparisons of influential factors based on the metabolic syndrome risk factors}

Among the variables the residence and past smoking duration were excluded because of limited small residence areas and limited smoking population. Continuous variables are categorized by considering the numbers of subjects and analyzed by two-way logistic regression.

\section{Comparisons of influential factors based on the normal group with the syndrome group}

According to Table 5, there were significant differences in two variables between normal group with no risk factor and metabolic syndrome group: age and BMI. Subjects over 70 years of age showed

Table 5. Comparisons of influential factors based on the normal group with the syndrome group

\begin{tabular}{|c|c|c|c|}
\hline Variable & $\operatorname{Exp}(B)$ & $95 \% \mathrm{Cl}$ & $P$-value \\
\hline \multicolumn{4}{|l|}{ Gender } \\
\hline Female & 1 & & \\
\hline Male & 1.570 & $0.368-6.700$ & 0.542 \\
\hline \multicolumn{4}{|l|}{ Age (yr) } \\
\hline$<60$ & 1 & & \\
\hline $60-69$ & 8.508 & $1.487-48.677$ & 0.016 \\
\hline$\geq 70$ & 9.137 & $1.751-47.685$ & 0.009 \\
\hline \multicolumn{4}{|l|}{ Smoking cigarette } \\
\hline No & 1 & & \\
\hline Yes & 1.162 & $0.241-5.599$ & 0.852 \\
\hline \multicolumn{4}{|l|}{ Drinking alcohol } \\
\hline No & 1 & & \\
\hline Yes & 1.504 & $0.343-6.584$ & 0.588 \\
\hline \multicolumn{4}{|c|}{ Intensive exercise } \\
\hline No & 1 & & \\
\hline Yes & 1.031 & $0.360-2.956$ & 0.955 \\
\hline \multicolumn{4}{|l|}{ Family history } \\
\hline \multicolumn{4}{|l|}{ No } \\
\hline Yes & 0.274 & $0.051-1.463$ & 0.130 \\
\hline \multicolumn{4}{|c|}{ Total cholesterol (mg/dL) } \\
\hline$<200$ & 1 & & \\
\hline $200-239$ & 2.562 & $0.773-8.487$ & 0.124 \\
\hline$\geq 240$ & 3.011 & 0.597-15.190 & 0.182 \\
\hline \multicolumn{4}{|c|}{ Body mass index $\left(\mathrm{kg} / \mathrm{m}^{2}\right)$} \\
\hline Normal & 1 & & \\
\hline$\geq$ Overweight & 8.732 & $2.818-27.059$ & 0.000 \\
\hline
\end{tabular}

$\mathrm{Cl}$, confidence interval.

$R^{2}=0.379$. significantly higher incidence (9.137 times) of the syndrome compared to the subjects lower than $60(P<0.01)$. BMI showed also significantly higher incidence (8.732 times) in overweight group compared to the normal group $(P<0.001)$.

\section{Comparisons of influential factors based on the one risk factor with syndrome group}

Table 6 demonstrates that there was significant difference in BMI between the syndrome group with one risk factor and 3 risk factors. BMI was significantly higher (5.282 times) compared to their counterpart $(P<0.001)$.

\section{Comparisons of influential factors based on the 2 risk factors with the syndrome group}

According to Table 7, there was significant difference in BMI between 2 risk factors and the syndrome group with more than

Table 6. Comparisons of influential factors based on the 1 risk factor with the syndrome group

\begin{tabular}{|c|c|c|c|}
\hline Variable & $\operatorname{Exp}(B)$ & $95 \% \mathrm{Cl}$ & $P$-value \\
\hline \multicolumn{4}{|l|}{ Gender } \\
\hline Female & 1 & & \\
\hline Male & 0.603 & $0.209-1.742$ & 0.350 \\
\hline \multicolumn{4}{|l|}{ Age (yr) } \\
\hline$<60$ & 1 & & \\
\hline $60-69$ & 2.695 & $0.683-10.642$ & 0.157 \\
\hline$\geq 70$ & 2.039 & $0.524-7.937$ & 0.304 \\
\hline \multicolumn{4}{|c|}{ Smoking cigarette } \\
\hline No & 1 & & \\
\hline Yes & 1.101 & $0.376-3.222$ & 0.861 \\
\hline \multicolumn{4}{|l|}{ Drinking alcohol } \\
\hline No & 1 & & \\
\hline Yes & 2.518 & 0.809-7.835 & 0.111 \\
\hline \multicolumn{4}{|c|}{ Intensive exercise } \\
\hline No & 1 & & \\
\hline Yes & 0.831 & $0.397-1.739$ & 0.623 \\
\hline \multicolumn{4}{|l|}{ Family history } \\
\hline No & 1 & & \\
\hline Yes & 0.631 & $0.247-1.615$ & 0.337 \\
\hline \multicolumn{4}{|c|}{ Total cholesterol (mg/dL) } \\
\hline$<200$ & 1 & & \\
\hline $200-239$ & 1.187 & $0.519-2.716$ & 0.685 \\
\hline$\geq 240$ & 1.045 & $0.380-2.874$ & 0.932 \\
\hline \multicolumn{4}{|c|}{ Body mass index $\left(\mathrm{kg} / \mathrm{m}^{2}\right)$} \\
\hline Normal & 1 & & \\
\hline$\geq$ Overweight & 5.282 & 2.420-11.532 & 0.000 \\
\hline
\end{tabular}

$\mathrm{Cl}$, confidence interval.

$\mathrm{R}^{2}=0.211$. 
Table 7. Comparisons of influential factors based on the 2 risk factors with the syndrome group

\begin{tabular}{|c|c|c|c|}
\hline Variable & $\operatorname{Exp}(B)$ & $95 \% \mathrm{Cl}$ & $P$-value \\
\hline \multicolumn{4}{|l|}{ Gender } \\
\hline Female & 1 & & \\
\hline Male & 0.765 & $0.274-2.137$ & 0.609 \\
\hline \multicolumn{4}{|l|}{ Age (yr) } \\
\hline$<60$ & 1 & & \\
\hline $60-69$ & 2.218 & $0.552-8.914$ & 0.262 \\
\hline$\geq 70$ & 1.320 & $0.331-5.265$ & 0.694 \\
\hline \multicolumn{4}{|l|}{ Smoking cigarette } \\
\hline No & 1 & & \\
\hline Yes & 0.724 & $0.224-2.337$ & 0.589 \\
\hline \multicolumn{4}{|l|}{ Drinking alcohol } \\
\hline No & 1 & & \\
\hline Yes & 2.085 & $0.653-6.654$ & 0.215 \\
\hline \multicolumn{4}{|c|}{ Intensive exercise } \\
\hline \multicolumn{4}{|l|}{ No } \\
\hline Yes & 0.942 & $0.349-2.544$ & 0.907 \\
\hline \multicolumn{4}{|l|}{ Family history } \\
\hline No & 1.294 & $0.460-3.643$ & 0.625 \\
\hline Yes & 0.757 & $0.295-1.946$ & 0.564 \\
\hline \multicolumn{4}{|c|}{ Total cholesterol (mg/dL) } \\
\hline$<200$ & 1 & & \\
\hline $200-239$ & 0.940 & $0.412-2.143$ & 0.883 \\
\hline$\geq 240$ & 0.757 & $0.282-2.035$ & 0.581 \\
\hline \multicolumn{4}{|c|}{ Body mass index $\left(\mathrm{kg} / \mathrm{m}^{2}\right)$} \\
\hline Normal & 1 & & \\
\hline$\geq$ Overweight & 4.094 & $1.959-8.552$ & 0.000 \\
\hline
\end{tabular}

$\mathrm{Cl}$, confidence interval.

$R^{2}=0.211$.

three risk factors and the incidence was significantly higher (4.094 times) in the overweight group than their counterpart $(P<0.001)$.

\section{DISCUSSION}

This study was performed to identify the differences of influential factors based on the risk factors on the development of the metabolic syndrome. Subjects were health screening examinee during January thru May in 2019 in Chungbuk district.

Different from the national health screening statistics which shows $22.8 \%$ of examinee were over 60 years old, the mean age of the subjects of the research were 71.3 years and $88.3 \%$ of the subjects were over 60 years. This is speculated that most of the subjects were residence of the rural area where the aged ratio is more than twice than that of the national aged population. The weekly number of intensive exercise was 2.3 on the average showing higher activity level that that of the national average of less than 1 in a week.

The incidence of the metabolic syndrome was $28.6 \%$ which is higher than the national screening statistics $(26.9 \%)$, but lower more than about $18 \%$ than that of the $46.4 \%$ of the statistics of the same age groups. It is thought that the difference was resulted from the difference of the race and the residence area (Moore et al., 2017).

Among the 5 diagnostic criteria for the metabolic syndrome risk factors, the ratio of abdominal obesity occupied $35.1 \%$, high insulin blood sugar $66.1 \%$, and triglyceride lipidemia $32.3 \%$, respectively. On the other hand, the ratios of high blood pressure and low HDL cholesterol showed lower than the national average (National Health Insurance Service, 2016).

Dividing the diagnostic numbers into $0,1,2$, and more than 3, the group of 0 was the youngest while identifying that the numbers and age do not show proportional relationship. This result shows the different tendency from the results which advocate diagnostic numbers increase as the age increases (Jamee et al., 2019; Kim et al., 2012; Li et al., 2016; Pérez et al., 2019).

Even the result showed desirable life style due to small ratio of smokers among subjects, BMI increased proportionally as the diagnostic number increase. According to the preceding researches (Bayoumi et al., 2019; Pérez et al., 2019), the ratio of normal weight group showed inverse proportion as the diagnostic numbers increase.

The results of comparisons among the groups with diagnostic numbers less than 3 and more than 3 revealed that BMI was the significant factor for the development of the metabolic syndrome regardless of the diagnostic numbers. In the group with 0 diagnostic number, age and BMI influenced the development of the metabolic syndrome (Hu et al., 2017; Johansson et al., 2012). BMI was the only factor affecting the development of metabolic syndrome when compared groups with 1 diagnostic number and with 2 diagnostic numbers. On the contrary, there was no significant difference of influencing factor between diagnostic numbers with 1 or 2 . As a result, groups with both 1 and 2 diagnostic numbers are regarded as the same groups. It would be effective to establish plans of health education in order to decrease obesity by BMI which is identified as a influential factor on the development of the metabolic syndrome.

Finally, it is meaningful that the characteristics related with metabolic syndrome of the aged in the rural area were identified. Furthermore, it is significant that the factors affecting the development of metabolic syndrome according to the diagnostic num- 
bers of risk factors were found thus suggesting the mediating direction of the health education. However, there were limited representative characteristics of the subjects because there were restricted numbers of some variables including smokers and alcohol drinkers. Therefore, it is speculated that further studies are required to clarify the influential factors developing metabolic syndrome such as exercise, smoking, or drinking alcohol.

\section{CONFLICT OF INTEREST}

No potential conflict of interest relevant to this article was reported.

\section{REFERENCES}

Bayoumi N, Helzner E, Afable A, Joseph M, Dhuper S. A real-world evaluation of a tertiary care childhood obesity intermention to reduce metabolic risk in a hard- to- reach urban population. BMC Pediatr 2019;19: 378.

Fan J, Liu Y, Yin S, Chen N, Bai X, Ke Q, Shen J, Xia M. Small dense LDL cholesterol is associated with metabolic syndrome traits independently of obesity and inflammation. Nutr Metab (Lond) 2019;16:7.

Hu L, Huang X, You C, Li J, Hong K, Li P, Wu Y, Wu Q, Wang Z, Gao R, Bao H, Cheng X. Prevalence of overweight, obesity, abdominal obesity and obesity-related risk factors in southern China. PLoS One 2017;12: e0183934.

Jamee AS, Aboyans V, Magne J, Preux PM, Lacroix P. The epidemic of the metabolic syndrome among the palestinians in the Gaza Strip. Diabetes Metab Syndr Obes 2019;12:2201-2208.

Johansson I, Nilsson LM, Stegmayr B, Boman K, Hallmans G, Winkvist A. Associations among 25-year trends in diet, cholesterol and BMI from 140,000 observations in men and women in Northern Sweden. Nutr J 2012;11:40.

Kim NL, Jeong HS, LeeDW, Shim MS, Te CH. Related clinical factors to number of diagnosing criteria of metabolic syndrome. J Health Info
Stat 2012;37:37-46.

Li R, Li W, Lun Z, Zhang H, Sun Z, Kanu JS, Qiu S, Cheng Y, Liu Y. Prevalence of metabolic syndrome in Mainland China: a meta-analysis of published studies. BMC Public Health 2016;16:296.

Mercado C, DeSimone AK, Odom E, Gillespie C, Ayala C, Loustalot F. Prevalence of cholesterol treatment eligibility and medication use among adults—United States, 2005-2012. MMWR Morb Mortal Wkly Rep 2015;64:1305-1311

Moore JX, Chaudhary N, Akinyemiju T. Metabolic syndrome prevalence by race/ethnicity and sex in the United States, National Health and Nutrition Examination Survey, 1988-2012. Prev Chronic Dis 2017;14: E24.

National Health Insurance Service. 2015 National Health Screening Statistical Yearbook. Wonju (Korea): National Health Insurance Service; 2016:742-828

National Health Insurance Service. 2016 National Health Screening Statistical Yearbook. Wonju (Korea): National Health Insurance Service; 2017: 740-827.

National Health Insurance Service. 2017 National Health Screening Statistical Yearbook. Wonju (Korea): National Health Insurance Service; 2018:1-12.

Pérez EA, González MP, Martínez-Espinosa RM, Vila MDM, Reig GarcíaGalbis M. Practical guidance for interventions in adults with metabolic syndrome: diet and exercise vs. changes in body composition. Int J Environ Res Public Health 2019;16:3481.

Pickens CM, Pierannunzi C, Garvin W, Town M. Surveillance for certain health behaviors and conditions among states and selected local areas behavioral risk factor surveillance system, United States, 2015. MMWR Surveill Summ 2018;67:1-90.

Reaven GM. Role of insulin resistance in human disease. Diabetes 1988; 37:1595-1607.

Yahia N, Brown CA, Snyder E, Cumper S, Langolf A, Trayer C, Green C. Prevalence of metabolic syndrome and its individual components among midwestern university students. J Community Health 2017;42: 674-687. 